\title{
General hospital services in the UK for adults presenting after self-harm: little evidence of progress in the past 25 years
}

\author{
Allan House and David Owens
}

\section{Summary}

Self-harm remains a serious public health concern, not least because of its strong link with suicide. Twenty-five years ago we lamented the deficits in UK services, research and policy. Since then, there has not been nearly enough effective action in any of these three domains. It is time for action.

\section{Keywords}

Psychosocial interventions; out-patient treatment; suicide: mental health services; self-harm.

\section{Copyright and usage}

(c) The Authors 2020.
Allan House (pictured) is Professor of Liaison Psychiatry in the School of Medicine University of Leeds. His current research interests include the role of social media in selfharm and new interventions for repeated self-harm. David Owens is an Associate Professor of Psychiatry in the School of Medicine, University of Leeds. He has longstanding interests in self-harm and suicide: clinical-, research- and policy-related.

Popular media coverage of self-harm tends to focus on the problem among young women, but in reality all ages and genders are affected. For example, more than $8 \%$ of the adult population in England report that they have harmed themselves at some time, ${ }^{1}$ leading to an estimated 200000 hospital attendances a year. Few of those who do not attend hospital will access specialist mental healthcare: a recent British study found that only $15 \%$ of those seen by their general practitioner after self-harm were referred to mental health services. ${ }^{2}$ A serious response to acts of self-harm whether they are seen as attempts at suicide or driven by other motives - as a public health concern must therefore include the role of hospital services as a key first-line resource used by people seeking help.

It is 25 years since we summarised the state of such hospital selfharm services as they were in the UK at that time, with the lament, 'haphazard clinical provision, little research, no central strategy'. What has changed in the intervening quarter century?

The problem has certainly not gone away. Indeed, figures suggest that the incidence of certain presentations of self-harm in the UK has increased in recent years. ${ }^{4}$ The likelihood of non-fatal repetition and of suicide is hugely raised after self-harm in adults: an estimated $1.6 \%$ of those seen in hospital after self-harm die by suicide in the next 12 months, ${ }^{5}$ and a quarter of all suicides in the UK have attended an acute hospital after self-harm within the past year. ${ }^{6}$ Although accurate figures have not been kept over the 25 years (a telling observation in its own right), a reasonable estimate from the numbers cited above would therefore be that there have been more than 4 million hospital attendances for self-harm since 1994, with at least 30000 of those attendances being followed by suicide within 12 months.

Considering the scale of self-harm in the general population, it is a pity that little progress has been made in clinical services. Most acute hospitals now have a mental health team that will see and assess people referred by staff after medical treatment. ${ }^{7}$ Such teams see on average (there is substantial variability between hospitals) only just over half of those who come to hospital. That means the other half leave hospital without even a brief specialist assessment of the reasons for their actions. Not surprisingly, therefore, only just over a quarter of those who come to hospital for treatment leave with arrangements for specialist mental health aftercare.

The picture of research into effective interventions is no more encouraging. Recent reviews ${ }^{8,9}$ have repeated a finding that is now decades old: multiple small research studies suggest a benefit for brief psychological treatments, but the evidence is not conclusive and what is needed are well-funded, large randomised trials of the sort that are routine in the evaluation of treatments for other lifethreatening conditions. For adults who attend hospital seeking help after self-harm, the UK's Medical Research Council has not funded a trial for more than 20 years. The Health Technology Assessment programme of the National Institute for Health Research, the main funder of such trials in the UK, has never funded a relevant trial in its more than 30 years.

The National Institute for Health and Care Excellence issues guidance on the best evidence-based practice and, not surprisingly given the lack of funded research, has not updated its two guidance papers on the management of self-harm for more than a decade. ${ }^{10,11}$ A critical report in 2018 from the Healthcare Safety Investigation Branch has at last led to a decision to update and merge the two reports; a process due to start in 2020 and welcome enough, although unlikely to effect a radical change in practice, given the lack of compelling new research evidence.

It is difficult to find much substance in government policy despite a continuing acknowledgement that self-harm is an important risk for eventual suicide - most recently, in the Department of Health's fourth progress report on its strategy on preventing suicides in England, published in 2019. ${ }^{12}$ The National Health Service's Five Year Forward View for Mental Health ${ }^{13}$ and their Long Term Plan ${ }^{14}$ contain little more than platitudes about the need for 'support'. Investment in liaison psychiatry teams in emergency departments is aimed at reducing waiting times and alleviating bed pressures; the teams have no remit to provide aftercare for people who self-harm. The Improving Access to Psychological Therapies service is reluctant to treat people they see as a suicide risk, and it certainly is not available as the main therapy service that follows assessment in hospital after an act of self-harm. 
Self-harm in adults represents the biggest identifiable risk for suicide, especially for men. Acute hospital emergency departments are the first port of call for many adults who have self-harmed and seek immediate help. The need is for substantial investment in, and improved coordination of, acute hospital services for mental healthcare beyond initial assessment, for funding of a sustained research programme aimed at developing and evaluating new interventions, and for properly funded policies to support these and related activities. The truth is that clinical services remain threadbare, research spending is still nugatory, and national policy is more akin to foot-shuffling than resolute, funded action. We must do better.

Allan House (1), Division of Psychological and Social Medicine, Leeds Institute of Health Sciences, School of Medicine, University of Leeds, UK; David Owens, Division of Psychological and Social Medicine, Leeds Institute of Health Sciences, School of Medicine, University of Leeds, UK

Correspondence: Allan House. Email: a.o.house@leeds.ac.uk

First received 4 Feb 2020, final revision 1 Apr 2020, accepted 6 Apr 2020

\section{Author contributions}

The authors contributed equally to the conception of this article, and to preparation of the manuscript.

\section{Declaration of interests}

A.H. receives funding from the National Institute for Health Research, for research into self-harm in adults.

ICMJE forms are in the supplementary material, available online at https://doi.org/10.1192/ bjp. 2020.85

\section{References}

1 McManus S, Hassiotis A, Jenkins R, Dennis M, Aznar C, Appleby L. Suicida thoughts, suicide attempts, and self-harm. In Mental Health and Wellbeing in England: Adult Psychiatric Morbidity Survey 2014 (eds McManus S, Bebbington
P, Jenkins R, Brugha T): Chapter 12. NHS Digital, 2016 (https://files.digital.nhs. uk/publicationimport/pub21xxx/pub21748/apms-2014-suicide.pdf).

2 Carr MJ, Ashcroft DM, Kontopantelis E, While D, Awenat Y, Cooper J, et al. Clinical management following self-harm in a UK-wide primary care cohort. J Affect Disorders 2016; 197: 182-8.

3 Owens D, House A. General hospital services for deliberate self-harm: haphazard clinical provision, little research, no central strategy. J Roy Coll Phys Lond 1994; 28: 370-1.

4 McManus S, Gunnell D, Cooper C, Bebbington PE, Howard LM, Brugha T, et al. Prevalence of non-suicidal self-harm and service contact in England, 2000-14: repeated cross-sectional surveys of the general population. Lancet Psychiatry 2019; 6(7): 573-81.

5 Carroll R, Metcalfe C, Gunnell D. Hospital presenting self-harm and risk of fatal and non-fatal repetition: systematic review and meta-analysis. PLOS One 2014; 9(2): e89944.

6 Department of Health. Preventing Suicide in England: A Cross-Government Outcomes Strategy to Save Lives. HMG/DH, 2012.

7 NHS. Report of the 4th Survey of Liaison Psychiatry in England (LPSE-4). NHS, 2019 (http://allcatsrgrey.org.uk/wp/download/public health/mental_health/ fourth-annual-survey-liaison-psychiatry-england-report.pdf [cited 24 April 2020]).

8 Hawton K, Witt KG, Taylor Salisbury TL, Arensman E, Gunnell D, Hazell P, et al. Psychosocial interventions for self-harm in adults. Cochrane Database of Systematic Reviews 2016; 5: CD012189. Available from: https://doi.org/10. 1002/14651858.CD012189.

9 Hetrick SE, Robinson J, Spittal MJ, Carter G. Effective psychological and psychosocial approaches to reduce repetition of self-harm: a systematic review, meta-analysis and meta-regression. BMJ Open 2016; 6(9): e011024.

10 National Institute for Health and Care Excellence. Self-Harm in Over 8s: ShortTerm Management and Prevention of Recurrence: Clinical Guideline [CG16]. NICE, 2004 (https://www.nice.org.uk/guidance/cg16).

11 National Institute for Health and Care Excellence. Self-Harm in Over 8s: LongTerm Management: Clinical Guideline [CG133]. NICE, 2011 (https://www.nice. org.uk/guidance/cg133)

12 Department of Health. Preventing Suicide in England: Fourth Progress Report of the Cross-Government Outcomes Strategy to Save Lives. HM Government London, 2019.

13 Independent Mental Health Task Force. The Five Year Forward View for Mental Health. NHS England, 2016 (https://www.england.nhs.uk/wp-content/ uploads/2016/02/Mental-Health-Taskforce-FYFV-final.pdf).

14 NHS England. The NHS Long Term Plan. NHS England, 2019 (https://www longtermplan.nhs.uk/publication/nhs-long-term-plan/). 